\title{
Clinico-Morphological Pattern of Breast Cancer at In patient Department of Dhaka Medical College Hospital - Study of 60 Cases
}

\author{
Nuruzzaman $\mathrm{HSM}^{1}$
}

\begin{abstract}
Background: Breast cancer incidence is increasing in Bangladesh with changing lifestyles, demographic and socioeconomic profiles. But there is no structured data on clinico-morphological pattern of breast cancer in Bangladesh. Understanding the clinical \& morphological pattern of breast cancer of this country will help in early detection \& prompt treatment of the cancer. Objective: To find out the clinical features of breast cancer $\&$ their morphological pattern at a tertiary level hospital. Methods: This is a cross sectional study. Data were collected prospectively from 60 new female patients with diagnosed breast carcinoma admitted to Dhaka Medical College Hospital at different surgical wards over a period of six months starting from 1st August 2010 to 28th February 2011 with the help of pre-designed semi-structured data collection form for clinical \& histopathological data. Male patients, severely ill patients and patients unwilling to take part in the study were excluded. Informed written consent was taken from each case. After analysis \& compilation the results were presented in tables, graphs and charts. Results: The mean age of breast cancer patients was 37.13 years. The average duration of symptoms of breast cancer patients before first presentation at tertiary level health facilities was 8.9 months. Most of the patients presented to tertiary level health facilities from 6 to 12 months after appearance of first symptom. Painless lump was the commonest presenting complaint with 43 cases, followed by nipple retraction in 24 cases, peu-de-orange in 21 cases, painful lump in 17 cases, ulceration in 12 cases and nipple discharge in 5 cases. $67 \%$ had tumor in the left breast whereas $28 \%$ had tumor in the right breast. Only 5\% cases presented with bilateral involvement. The most frequent location of primary tumor was upper outer quadrant which is 32 cases followed by central in 9 cases, lower outer in 8 cases, lower inner in 6 cases, upper inner in 3 cases and overlapping lesions in 2 cases. Majority of the patient $(69 \%)$ presented with a tumor size of more than $5 \mathrm{~cm}$ whereas only $3.3 \%$ patients presented with tumor size of less than or equal to 2 $\mathrm{cm}$. Axillary lymph nodes were involved in most of the cases(86.66\%). Infiltrating ductal carcinoma, NOS (which is an abbreviation for nothing otherwise specified) was the commonest (98.33\%) histopathological variant. Most of the patients of this series, i.e. 35 patients had poorly differentiated tumor. 4 patients had well differentiated tumor and 21 patients had moderately differentiated tumor. Conclusion: In my study breast cancer is found to be common among relatively younger age group, majority below 40 years. The patients of breast cancer are coming to a tertiary level hospital very late, mostly with clinical features of advanced disease. For better understanding a series of multi centre studies are needed.[J Shaheed Suhrawardy Med Coll 2015;5(2): 49-53]
\end{abstract}

Keywords: Breast cancer, clinico-morphological pattern, Dhaka Medical College Hospital

Received: December 2012; Revised: March 2013; Accepted: May 2013

\section{Introduction}

Breast cancer is the most frequently diagnosed cancer in women worldwide with an estimated 1.4 million new cases in 2008. Also it is the leading cause of cancer death in women worldwide ${ }^{1}$. Though over $50 \%$ of breast cancer incidence occurs in developed world, especially Europe \& North America, it's incidence is increasing in areas like Africa \& Asia, which have had low rates previously ${ }^{2,3,4}$. In
Bangladesh, it is the most common cancer among women \& has overtaken cervix cancer, which was the commonest cancer a decade $\mathrm{ago}^{5}$. The increasing incidence of breast cancer in countries like Bangladesh are may be due to changing lifestyles, demographic and socioeconomic profiles. Moreover the data regarding the disease are inadequate. The continuing rise in breast cancer incidence has created an urgent need to develop strategies for early

1. Dr. Hasan Shahriar Md. Nuruzzaman, Junior Consultant, Department of Surgery, Shaheed Suhrawardy Medical College Hospital, Dhaka.

\section{Correspondence}

Dr. Hasan Shahriar Md. Nuruzzaman, Junior Consultant, Department of Surgery, Shaeed Suhrawardy Medical College Hospital, Sher-e-Bangla Nagar, Dhaka-1207, Bangladesh. E-mail: kallol55@hotmail.com; Cell no.+88-01819-287064 
detection and treatment. Modes of presentation of breast cancer in our population may not be the same as of the western population due to different hormonal, genetic and environmental factors. Breast cancer screening program is not available in our country due to financial constraints. So early detection of lump and seeking early treatment may be the key to better management in country like ours. The study was done mainly to know the common modes of presentation $\&$ the morphological pattern of breast cancer at in patient department of a tertiary level hospital of Bangladesh i.e. Dhaka Medical College Hospital.

\section{Patients and methods:}

This descriptive type cross sectional study was carried out in different surgical wards of Dhaka medical college Hospital over a period of six months starting from 1st August 2010 to 28th February 2011. A total of 60 female patients with diagnosed breast carcinoma admitted to Dhaka Medical College Hospital during the study period were enrolled in the study as case in this study. Data were collected by purposive sampling, all inclusive who gave informed written consent after admission into the hospital with the help of a Pre-designed semi-structured data collection form for clinical \& histopathological data. Male patients, severely ill patients and patients unwilling to take part in the study were excluded from the study. All consecutive samples were included. A written Informed consent was taken from each case. A detailed history was taken and clinical examination was done meticulously to elicit different breast signs and the axillary lymph node. The diagnosis of carcinoma breast along with histomorphological type and tumor grading was later confirmed by histopathology. At the end of the study the data were compiled and analyzed. Then the results were presented in tables, graphs and charts.

\section{Results:}

The mean age was 37.13 years. The youngest patient in this series was 22 years old and the eldest was 57 years. More than half of the patients were in their thirties (61.66\%). 41-50 years age group was the second most common.

\section{Table I: Age distribution of breast cancer $(n=60)$}

\begin{tabular}{lcc}
\hline Age group(in years) & Number of patients & Percentage \\
\hline $21-30$ & 9 & 15 \\
$31-40$ & 37 & 61.66 \\
$41-50$ & 10 & 16.66 \\
$51-60$ & 4 & 6.66 \\
\hline
\end{tabular}

The average duration of symptoms of breast cancer patients before first presentation at tertiary level health facilities was 8.96 months. Most of the patients presented to tertiary level health facilities 6 to 12 months after appearance of first symptom. The number of cases in this group is $41(68.33 \%)$. 13 cases $(21.66 \%)$ came to the tertiary level hospital within 6 months of their symptoms. 6 cases $(10 \%)$ came very late, i.e. after more than 12 months.

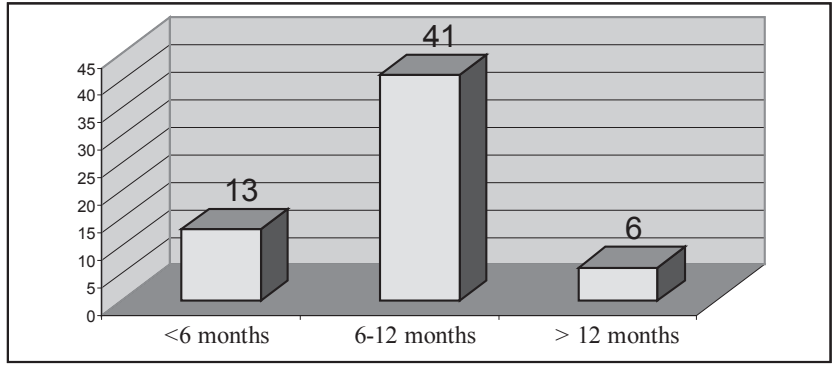

Figure I: duration of symptoms before first presentation at tertiary health care facilities

Painless lump was the commonest presenting complaint with $43(71.66 \%)$ cases, followed by nipple retraction in $24(40 \%)$ cases, peu-de-orange in $21(35 \%)$ cases, painful lump in 17 $(28.33 \%)$ cases, ulceration in $12(20 \%)$ cases and nipple discharge in $5(8.33 \%)$ cases.

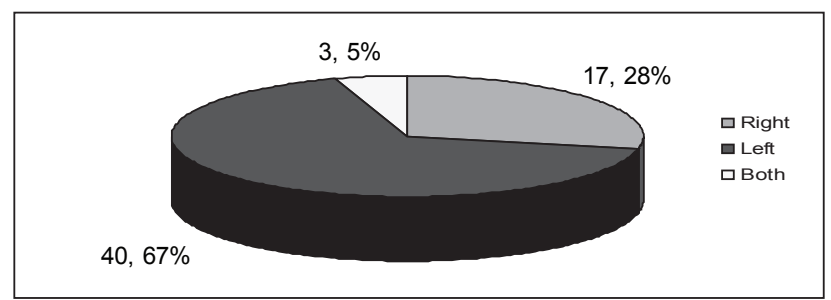

Figure II: Distribution of breast cancer according to the involvement of breast $(n=60)$

The most frequent location of breast lump was upper outer quadrant. It was found in 32 cases $(54 \%)$ followed by central in 9 cases $(15 \%)$, lower outer in 8 cases $(13 \%)$, lower inner in 6 cases $(10 \%)$, upper inner in 3 cases $(5 \%)$ and overlapping lesions in 2 cases $(3 \%)$.

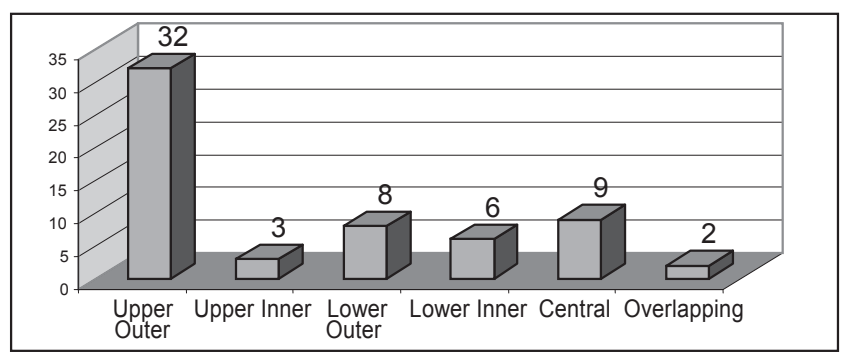

Figure III: Location of Breast lump by quadrant of breast $(\mathrm{n}=60)$

Majority of the patient i.e. 41 cases (69\%) presented with a tumor size of more than $5 \mathrm{~cm} .17$ patients presented with tumor size of more than $2 \mathrm{~cm}$ to $5 \mathrm{~cm}$. only 2 patients presented with tumor size of less than or equal to $2 \mathrm{~cm}$.

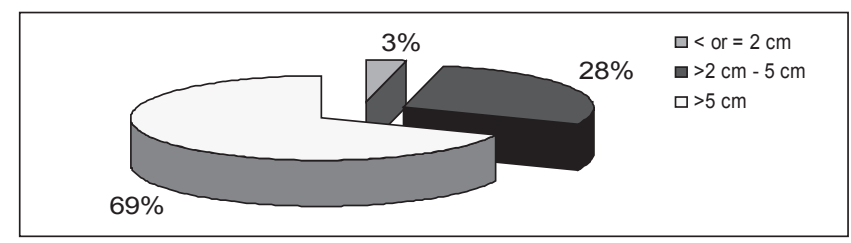

Figure IV: Size of the tumor $(\mathrm{n}=60)$

Axillary lymph nodes were palpable in 52 cases (86.66\%). 8 patients did not have any palpable Axillary lymph nodes. 


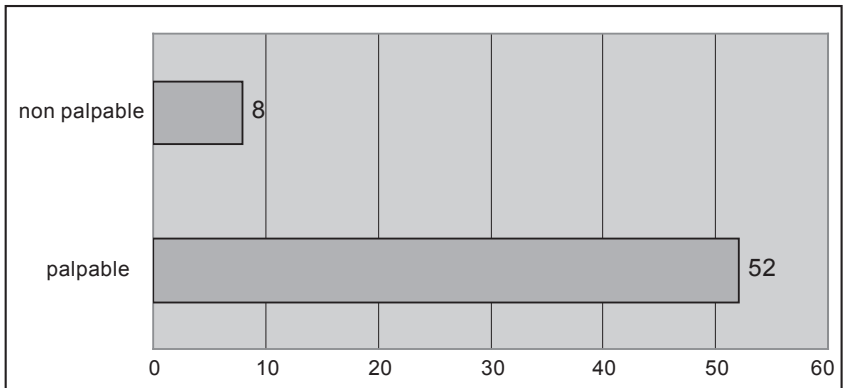

Figure V: Palpable axillary lymph nodes $(n=60)$

Among the 52 patients having palpable Axillary lymph nodes, 25 cases $(48 \%)$ presented with 1 group involved. 12 cases (23\%) had 2 groups involved and 15 cases (29\%) had more than 2 groups of Axillary lymph nodes involved.

The average number of involved nodes per patient is 2.88 .

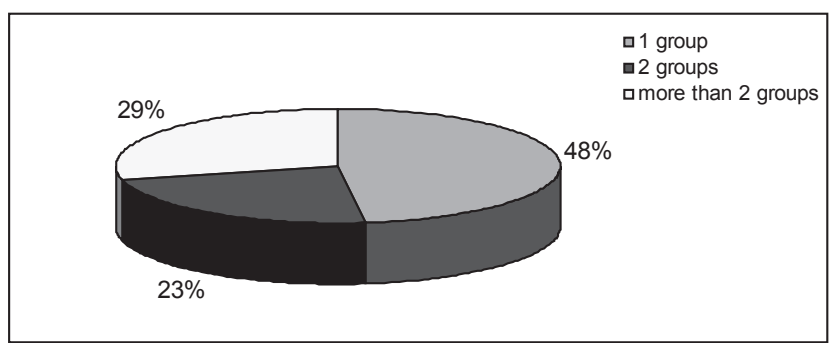

FIGURE VI: Number of Groups of Axillary nodes involved in breast cancer patients $(n=60)$

In 59 cases (98.33\%), histopathology showed Infiltrating ductal carcinoma, NOS (which is an abbreviation for nothing otherwise specified). Only in 1 case (1.66\%) histopathology showed infiltrating lobular carcinoma.

Table II: Distribution of cases according to histo-morphological types $(n=60)$

\begin{tabular}{lcc}
\hline $\begin{array}{l}\text { Histo-morphologica } \\
\text { I type }\end{array}$ & $\begin{array}{c}\text { Number of } \\
\text { patients }\end{array}$ & Percentage \\
\hline $\begin{array}{l}\text { Infiltrating ductal } \\
\text { carcinoma, NOS }\end{array}$ & 59 & 98.33 \\
\hline $\begin{array}{l}\text { Infiltrating lobular } \\
\text { carcinoma }\end{array}$ & 1 & 1.66 \\
\hline
\end{tabular}

Most of the patients of this series, i.e. 35 patients $(58.33 \%)$ had poorly differentiated tumor. Four patients $(6.66 \%)$ had well differentiated tumor and 21 patients $(35 \%)$ had moderately differentiated tumor.

Table II: Distribution of cases according to histo-morphological types $(n=60)$

\begin{tabular}{lcc}
\hline Grade & Number of patients & Percentage \\
\hline Grade I & 4 & 6.66 \\
Well differentiated & 21 & 35 \\
\hline $\begin{array}{l}\text { Grade II } \\
\text { Moderately differentiated }\end{array}$ & 35 & 58.33 \\
\hline $\begin{array}{l}\text { Grade III } \\
\text { Poorly differentiated }\end{array}$ & 35 \\
\hline
\end{tabular}

\section{Discussion}

Every year in Bangladesh approximately 35,000 women develop breast cancer many of whom never seek treatment ${ }^{6}$. Prompt diagnosis and treatment provides the best chance of long term survival but for many reason Bangladeshi women do not seek treatment early and often presented at an advanced stage of the disease ${ }^{6}$.

Age of the cancer patient is an important factor both for occurrence and management of the case. The incidence of the breast cancer increases as the age increases? Previously in USA and other western countries the age distribution at diagnosis was bimodal with a dominant peak frequency near the age 50 years and a smaller peak near the age 70 years. But during 2000 to 2003 the bimodal age distribution returned to predominantly younger age at onset but still a peak frequency near age 50 years ${ }^{7}$. Goel A, Bhan C et al (2003) in a five year clinico-pathological study between 1997 to 2002 in India found breast cancer most common in 30-40 years age group $^{8}$. Saxena $\mathrm{S}$ et al (2005) also in India found the average age was 47.9 years 9 .

In this study breast cancer was found to be most common in age group 31-40 years $(61.66 \%)$ followed by age group $41-50$ years $(16.66 \%)$ with the average age of 37.13 years. $\&$ the findings are consistent with the Indian studies.

Yoo K-Y, Kang D et al in Korea and Mousavi SM and Montazeri A in Iran found breast cancer to be most prevalent in 40-49 years age group ${ }^{10,11}$. The reason for early age of occurrence amongst Bangladeshi females needs to be further studied. A similar viewpoint has been put forward by a study conducted by Borovanova in the Czech population. In their study also, they found a shift of cancer more towards younger women ${ }^{12}$.

The average duration of symptoms of breast cancer patients before first presentation at tertiary level health facilities was 8.9 months. Most of the patients presented to tertiary level health facilities after 6 to 12 months of appearance of first symptom. There are many reasons behind these late presentations. The female patients are neglected. Lack of education, poor socio-economic condition, poor access to tertiary center, ignorance, social prejudice, religious bindings, dependency on indigenous medicine, fear of surgery - all cause early detection of breast cancer almost impossible in our country. Similar trend was seen in another study in Pakistan where it was shown that the frequency of advanced malignancy was alarmingly high in younger patients ${ }^{13}$.

In the present study $71.66 \%$ cases presented with painless lump, $28.33 \%$ with painful lump, $20 \%$ with ulceration, $8.33 \%$ with nipple discharge and $40 \%$ with nipple retraction. Personal series performed by Haagensen ${ }^{14}$ shows that $75 \%$ to $80 \%$ of women suffering from carcinoma breast presents with a lump in the breast. Nair et $\mathrm{al}^{15}$ have shown that lump in the breast was the presenting symptom in $88 \%$, ulceration $8 \%$ and nipple retraction in $8 \%$ cases. Another study was carried out by Vinod Raina et $\mathrm{al}^{16}$ in India, where $96 \%$ of the patient in premenopausal women presented with breast lump, 15.8\% with pain and $4.4 \%$ came with nipple discharge.

In the current series, left breast was affected in $67 \%$ cases, $28 \%$ in the right breast and the rest had bilateral involvement. Classically there is a left sided 
predominance ${ }^{17}$. The side affection possibly does not have much effect so far the treatment and prognosis are concerned.

In this study the most frequent site involved was upper outer quadrant (in 54\% cases). In 15\% cases it was central, $13 \%$ in Lower outer quadrant, $10 \%$ in lower inner, $5 \%$ in upper inner quadrant and overlapping lesions were in $3 \%$ cases. A study carried out in Kerala, India ${ }^{15}$ has shown $31 \%$ of the growth in upper-outer quadrant, $8 \%$ in lower-outer quadrant, $11 \%$ in the upper-inner and $29 \%$ affected the whole breast. In a personal series of Haagensen ${ }^{14}$ upper outer quadrant tumour was $38.5 \%$, upper inner quadrant tumor was $15.3 \%$, lower outer quadrant tumor was $8.8 \%$, lower inner quadrant tumor was $6.6 \%$ and sub-areolar tumor was $29 \%$.

The majority of the patient in the current series (69\%) presented with a tumor more than $5 \mathrm{~cm}$ in diameter which denotes a higher stage. $28 \%$ presented with a tumor $2-5$ $\mathrm{cm}$ and only $3 \%$ with a tumor size below $2 \mathrm{~cm}$. A study carried out in USA by G. Marie Swanson et al18 showed that $65.5 \%$ of the younger women presented with a lump more than $2 \mathrm{~cm}$ in diameter. Another study carried out by Raina V et $\mathrm{al}^{16}$ showed $74.1 \%$ patients presented with tumor size more than $2 \mathrm{~cm}$ but less than $5 \mathrm{~cm}$ and $12.3 \%$ with tumor size more than $5 \mathrm{~cm}$. This shows that our patients present quiet late $\&$ with a higher stage of disease to a tertiary center.

In the present series, among the 60 patients, 52 patients had clinically palpable lymph nodes $(86.66 \%)$. Among them $48 \%$ had one group of lymph node involved, $23 \%$ had two groups and $29 \%$ had more than two groups involved. The rest $(13.33 \%)$ had no lymph node palpable clinically. A study done by Zaghloul AS et $\mathrm{al}^{19}$ showed similar sorts of results.

Histology as a prognostic factor has been well documented. Patients with histology of Infiltrating duct carcinoma (IDC)(NOS) have a poor survival compared to other types ${ }^{4}$. In the present study among the different histomorphological types, Infiltrating duct Carcinoma (NOS) was found to be the most common type (98.33\%). Infiltrating lobular carcinoma was found in $1.66 \%$ cases. In this series no other variety was found. Saxena et al showed in their series that infiltrating duct carcinoma (NOS) was found to be the most common type i.e. in $86.9 \%$ cases $^{9}$. In study carried out by Raina V et al, $92.8 \%$ were infiltrating duct carcinoma, $2.9 \%$ were infiltrating lobular carcinoma and $1.4 \%$ were medullar variety ${ }^{16}$.

$58.33 \%$ of the patients of this series had well differentiated tumor (grade III). 35\% had moderately differentiated tumor (grade II) and only $6.66 \%$ had poorly differentiated tumor (grade I). Perkins CI et al had shown that $41 \%$ of his patients were grade I, $48.8 \%$ were grade II and $3.8 \%$ were grade III $^{20}$.

\section{Conclusion}

From this study and the studies in other regional countries, it is clearly evident that breast cancer is becoming common among relatively younger age group. In the current study majority of the patients were below 40 years. So the present western screening recommendation of mammography at the age of 40 years, which are being followed, should be changed in our country \& should be started earlier as disease is more prevalent in younger age group. Moreover, patients of breast cancer are coming to a tertiary level hospital very late, mostly with clinical features of advanced disease. Social awareness is very important in this aspect. So that the males, who in most cases take the decision of the family matters, take their wives, sisters and mothers to healthcare facilities having treatment of breast cancer as soon as the disease has been suspected.

This small study may not represent the total breast cancer scenario in Bangladesh. To validate the result of this study a series of multi centre studies are needed to identify the exact clinico-morphological features of breast cancer and to formulate a screening \& management guideline in our context.

\section{Acknowledgement:}

1. Professor Dr. S M Amjad Hossain, Head, Department of Surgery, Saheed Suhrawardy Medical College Hospital, Sher-e-Bangla Nagar, Dhaka.

2. Dr. Muhammad Zillur Rahman Khan, Assistant Professor of Child, Adolescent \& Family Psychiatry, National Institute of Mental Health \& Research, Dhaka.

\section{Source of Fund:}

There is no additional fund except that of the researcher's himself.

\section{References}

1) American Cancer Society. Global Cancer Facts \& Figures 2nd Edition.

Atlanta: American Cancer Society; 2011; 11:11-12

2) Althuis MD, Dozier JM, Anderson WF et al; Global Trends in Breast Cancer incidence and Mortality 1973-1997. International Journal of Epidemiology 2005; 34: 405-412.

3) Ito Y, Ioka A, Tanaka M, Nakayama T, Tsukuma H. Trends in cancer incidence and mortality in Osaka, Japan: Evaluation of cancer control activities. Cancer Sci. Aug 11 2009; 100:2390-2395

4) Rao DN, Dinshaw KA: Epidemiological review: In Risk factors and survival rates. Hospital Cancer Registry. Division of Epidemiology and Biostatistics. Tata Memorial Hospital Mumbai 1999, 1-7

5) Cancer Registry Report : National Institute of Cancer Research and Hospital 2005-2007

6) Love R. Hope for Breast Cancer in Bangladesh. Dhaka, June26, 2006. American Center Press Section Release.

7) Bray F, McCarren P, Parkin DM; The Changing Global Pattern of Female Breast Cancer Incidence and Mortality. Breast Cancer Res 2004; 6:229-239

8) Goel A, Bhan CM et al; Five year clinico pathological study of breast cancer. Indian Journal of Medical Science 2003; 57(8): 347-349.

9) Saxena S, Rekhi B et al; Clinico-morphological patterns of breast cancer including family history in a New Delhi hospital, India-A cross-sectional study. World Journal of Surgical Oncology 2005, 3:67 doi: 10, 1186/1477-7819-3-67.

10) Yoo K-Y, Kang D et al; Epidemiology of breast cancer in Korea: occurrence, high-risk groups, and prevention. Korean Med Sci. 2002 February; 17(1): 1-6.

11) Mousavi SM, Montazeri A et al; Breast cancer in Iran: An epidemiological review. Breast journal 2008; 13 1(4): 383-391. 
12) Borovanova T, Soucek P: Breast cancer: An overview of factors affecting the onset and development of the disease. Cab Lek Cesk 2002, 141:80-89.

13) Malik AM, Pathan R, Shaikh NA, Qureshi JN, Talpur KAH: Pattern of presentation and management of $\mathrm{Ca}$ breast in developing countries. There is a lot to do. JPMA 60:718; 2010.

14) Haagensen CD. Disease of Breast, 3rd edn. W.B. Saunders, Philadelphia: 1986

15) Nair MK; Overall survival from breast cancer in Kerala,India, in relation to menstrual,reproductive and clinical factors.Cancer 1993;71:1791-6.

16) Raina V,Bhutani M, Bedi R, Sharma A, Deo SV, Shukla NK, Mohanti BK, Rath GK; Clinical features and prognostic factors of early breast cancer at a major cancer center in North India. Indian Journal of Cancer,2005; 42(1):40-45.

17) Kumar V, Abbas AK, Fausto N; Robbin's and Cortan Pathologic Basis of Disease, 7th edn.Elsevier Saunders,Philadelphia;2004:1129-1149.

18) Swanson GM, Haslam SZ; Breast cancer among young African-American women. American Cancer Society Journal, 2005; 97(1-suppl):273-279

19) Zaghloul AS, Ghoneim WA, El-Moneim TA, Kaddah NT, El-Bolkainy N, Khafagy MM; Patterns of Axillary Lymph Node Metastasis from Breast Cancer in Egyptian Patients. Journal of the Egyptian Nat. Cancer Inst. 2001;13(1):1-8

20) Perkins CI, Moris CR. Cancer incidence and mortality in California by detailed race/ethnicity 1988-1992. Sacromento, CA. Dept. of Health Service; Cancer Surveillance section, April 1995.

PROM study). New England Journal of Medicine, 334(16), 1005-1010.

12. Zanzami, Y. (2005)Prelabor Rupture of membranes at term in low-risk women: induce or wait? Achieves of Gynecology and Obstetrics, Oct. 6: $1-5$.

Table- 1: Prevalence of PROM among all Obstetrics patients $(\mathrm{n}=1879)$ 